\title{
Licitações públicas e sustentabilidade: uma análise da aplicação de critérios ambientais nas compras de órgãos públicos federais em Florianópolis (SC)
}

\author{
Public bidding and sustainability: an application analysis of
} environmental criteria in the purchase of federal public agencies in Florianópolis (SC)

\author{
José Sérgio da Silva Cristóvam* \\ Universidade Federal de Santa Catarina (Brasil) \\ jscristovam@gmail.com \\ Hulisses Fernandes** \\ Universidade Federal de Santa Catarina (Brasil) \\ hulissesf@hotmail.com
}

* Professor Adjunto de Direito Administrativo no Curso de Graduação em Direito e no Programa de Mestrado em Direito do PPGD da Universidade Federal de Santa Catarina - UFSC (Florianópolis-SC, Brasil). Doutor em Direito Administrativo pela UFSC (2014), com estágio de Doutoramento Sanduíche junto à Universidade de Lisboa - Portugal (2012). Mestre em Direito Constitucional pela UFSC (2005). E-mail: jscristovam@gmail.com.

** Bacharel em Direito pelo CCJ da Universidade Federal de Santa Catarina - UFSC (Florianópolis-SC, Brasil). Analista Tributário da Receita Federal do Brasil. E-mail: hulissesf@hotmail.com. 


\section{Resumo}

Pretende-se a análise da aplicação de critérios de sustentabilidade ambiental nas compras de órgãos públicos federais, mais especificamente aqueles sediados em Florianópolis (SC), no biênio 2015/2016. Desde o advento da Lei n. 12.349/2010, que modificou a redação do art. 3o da Lei n. 8.666/1993, além de escolher a melhor proposta econômica, a lei passou a estampar a finalidade de promoção do desenvolvimento nacional sustentável, por meio da inserção de critérios ambientais. A proposta mais vantajosa não é apenas aquela que atenda a questão financeira, mas sim um conjugado de economia e sustentabilidade ambiental. A Administração Pública tem o dever de promover compras públicas comprometidas com o desenvolvimento sustentável, quer pela sua condição de consumidor ou por ser agente público responsável pela regulação da ordem econômica. O procedimento aplicado é o estudo de caso. $O$ método de abordagem adotado é a análise de conteúdo e a técnica utilizada é a coleta e análise quantitativa e qualitativa dos editais de licitações. O estudo de caso indica uma porcentagem de $47,74 \%$ de inserção de critérios de sustentabilidade dos 50 (cinquenta) editais de licitação coletados, a demonstrar uma baixa adesão (análise quantitativa). E a maioria dos critérios é inserida sem a individualização na respectiva descrição de cada item (análise qualitativa). Em conclusão, nota-se um enorme potencial a ser utilizado na prática das licitações sustentáveis.

Palavras-chave: licitações públicas; sustentabilidade; meio ambiente; fomento do Estado; desenvolvimento nacional sustentável.

\section{Abstract}

The paper aims to analyze the application of environmental sustainability criteria in the purchases of federal public agencies, specifically those based in Florianópolis (SC), in the 2015/2016 biennium. Since the advent of Law $n .12,349 / 2010$, which modified the wording of art. 3o of Law $n .8,666 / 1993$, in addition to choosing the best economic proposal, the law started to stamp the purpose of promoting sustainable national development through the insertion of environmental criteria. The most advantageous proposal is not only one that addresses the financial issue, but a combination of economy and environmental sustainability. The Public Administration has the duty to promote public purchases committed to the sustainable development, either by its condition of consumer or by being public agent responsible for the regulation of the economic order. The procedure applied is the case study. The approach adopted is content analysis and the technique used is the collection and quantitative and qualitative analysis of bids. The case study indicates a percentage of $47.74 \%$ inclusion of sustainability criteria of the fifty (50) bidding documents collected, demonstrating a low adhesion (quantitative analysis). And most of the criteria are inserted without the 
individualization in the respective description of each item (qualitative analysis). In conclusion, there is an enormous potential to be used in the practice of sustainable biddings.

Keywords: public bidding; sustainability; environment; promotion of the State; Sustainable national development.

\section{Sumário}

1. Introdução. 2. Sobre as finalidades das licitações públicas. 2.1 A Lei n. 12.349/2010 e a Instrução Normativa n. 01/2010 da SLTI/MPOG. 3. Sobre o marco normativo constitucional da proteção ao meio ambiente pelo Estado e o paradigma da sustentabilidade. 4. A função fomentadora do Estado nas licitações públicas e o paradigma da sustentabilidade. 5. A aplicação dos critérios de sustentabilidade ambiental por órgãos públicos federais em Florianópolis (SC) - biênio 2015/2016. 5.1 Análise quantitativa dos critérios sustentáveis. $\mathbf{5 . 2}$ Análise qualitativa dos critérios sustentáveis. 6. Considerações finais. Referências.

\section{Introdução}

A proteção ao meio ambiente é temática recorrente nas pautas de discussões mundiais, mais expressivamente desde a Declaração da Conferência das Nações Unidas sobre Meio Ambiente Humano, que em seu art. 2o já trazia as bases para a ideia de sustentabilidade ambiental. ${ }^{1}$ Neste debate, outro marco histórico foi a Conferência da Organização das Nações Unidas ocorrida no Rio de Janeiro em 1992, conhecida como ECO/92, com a aprovação da Agenda 21, que em seu item 3.4 expressa como principal objetivo "capacitar todas as pessoas a atingir meios sustentáveis de subsistência, devendo ser um fator de integração que permita às políticas abordar simultaneamente questões de desenvolvimento, de manejo sustentável dos recursos e de erradicação da pobreza" (ONU, Agenda 21, 1992).

No âmbito do discurso jurídico-normativo, a sustentabilidade ganha um contorno de princípio fundamental de toda a ordem constitucional, inclusive com a firme colonização estruturante de todo o regime jurídicoadministrativo, ${ }^{2}$ em especial se entendido a partir das balizas renovadoras

\footnotetext{
${ }^{1}$ Sobre o tema, cumpre destacar: "Os recursos naturais da Terra, incluindo o ar, a água, a terra, a flora e a fauna e, especialmente as amostras representativas dos ecossistemas naturais, devem ser preservados em benefício das gerações presentes e futuras, através de planejamento ou gestão cuidadosa, como apropriado" (ONU, 1972).

2 Sobre o tema, ver: FREITAS, 2016.
} 
trazidas pela Constituição de $1988 .{ }^{3}$ Uma das novidades nesse debate é a atuação do Estado pela via da sua função fomentadora, com o incentivo à sustentabilidade ambiental a partir das contratações públicas. No Brasil, essa disposição instrumental foi expressamente incorporada à legislação com o advento da Lei n. 12.349/2010, que alterou o art. 3o da Lei 8.666/1993, regulamentado pelo Decreto n. 7.746/2012 (BRASIL, 2010; 2012).

Nesse cenário, um dado desponta com central relevância: estima-se que mais de $10 \%$ do Produto Interno Bruto brasileiro (PIB) pode ser imputado às contratações públicas, podendo chegar a 15\%, conforme dados do Governo Federal (Portal, 2016). Disso decorre um papel inarredável ao Poder Público, não somente de funcionar um consumidor consciente, mas especialmente fomentar políticas de responsabilidade socioambiental no setor privado. O impacto econômico das compras governamentais e seu poder de indução do mercado constituem fatores chave para a implementação de licitações sustentáveis.

A licitação, antes encarada apenas como meio para a Administração Pública atender à sua necessidade e garantir um processo competitivo, que assegurasse tratamento isonômico e a contratação do melhor preço, hoje ganha uma dimensão instrumental para o desenvolvimento nacional sustentável, a partir da inclusão de critérios de sustentabilidade nas contratações públicas. Nada obstante, a disposição normativa de inclusão de critérios sustentáveis nos editais ainda parece tímida e por vezes mesmo ausente em vários órgãos governamentais. ${ }^{4}$

O presente trabalho tem por objeto central a análise do papel do Estado no fomento ao desenvolvimento sustentável, pela via das compras públicas, mais especificamente sobre a utilização de critérios de sustentabilidade por órgãos públicos federais localizados em Florianópolis

\footnotetext{
${ }^{3}$ Sobre o novo regime jurídico-administrativo, inclusive com a ressignificação do paradigma tradicional, fundado no princípio estruturante da supremacia do interesse público sobre o particular, importa ressaltar que, em um modelo de Estado constitucional de direito, fundado na defesa e promoção dos direitos fundamentais e respeito à dignidade humana, as relações do Poder Público com os cidadãos acaba por ser vivamente contagiada pelo movimento de personalização do Direito Administrativo. Disso resulta um redimensionamento do regime jurídico-administrativo, adequando o conceito de interesse público aos direitos fundamentais e à dignidade humana, do que resulta o deslocamento da centralidade normativa do Estado para a pessoa humana. Este novo modelo agasalha em plenitude e na mais viva potência o princípio estruturante da sustentabilidade e o paradigma das licitações sustentáveis, porquanto a preservação ambiental ancora-se no respeito aos direitos fundamentais e na dignidade da pessoa humana. Sobre o tema, ver: CRISTÓVAM, 2015.

${ }^{4}$ Sobre o tema, ver: MASTRODI; BRITO, 2017; FINGER; QUETES, 2014; MATA DIZ; CALDAS, 2016.
} 
(SC), no biênio 2015/2016, a partir de uma amostragem de 50 (cinquenta) pregões eletrônicos, bem como o modo de inclusão dos respectivos critérios de sustentabilidade ambiental. Antes, porém, mostra-se relevante um breve estudo sobre as finalidades das licitações públicas.

\section{Sobre as finalidades das licitações públicas}

Para os limites deste estudo, cumpre assentar que o ordenamento jurídico brasileiro determina que as contratações públicas sigam o princípio do procedimento formal, de maneira a assegurar a igualdade de participação dos interessados, bem como atingir a proposta mais vantajosa para a Administração Pública. Portanto, a licitação pode ser conceituada como um procedimento administrativo, mediante uma sucessão de atos previstos em lei e que proporciona a seleção da proposta mais vantajosa pelo Poder Público, com a observância dentre outros dos princípios da isonomia, da eficiência e da moralidade na contratação administrativa. ${ }^{5}$

Com efeito, o princípio da isonomia na obtenção da proposta mais vantajosa é central ao certame licitatório. O Poder Público não pode escolher indiscriminadamente a melhor contratação segundo critérios subjetivos que possam beneficiar os futuros contratados e/ou seus agentes. Em verdade, é necessário que a escolha decorra de critérios objetivos de forma a garantir a igualdade de condições entre os participantes e o respeito ao próprio princípio republicano. ${ }^{6}$

Cumpre ressaltar que a isonomia possui uma dupla disposição instrumental e substancial aos certames licitatórios. Primeiramente, assegura a oportunidade de ampla participação de qualquer interessado no certame licitatório, desde que tenham condições de assegurar o cumprimento do futuro e eventual contrato. E, também, impõe o dever de igualdade de tratamento a todos os participantes interessados, de forma a assegurar um julgamento de propostas livre de restrições discriminatórias ou desamparadas de base legal.

Por certo, não se pode admitir cláusulas ou condições que frustrem o caráter competitivo dos certames licitatórios, salvo se tais restrições tenham fundamento na garantia da execução do contrato ou promoção de alguma

\footnotetext{
${ }^{5}$ Sobre o tema, ver JUSTEN FILHO, 2016. A respeito dos princípios da contratação pública numa perspectiva global, ver: RODRÍGUEZ-ARANA MUÑOZ, 2016.

${ }^{6}$ Sobre as práticas de corrupção no âmbito das licitações, ver: FORTINI; MOTTA, 2016.
} 
Licitações públicas e sustentabilidade: uma análise de aplicação de critérios ambientais nas compras dos órgãos públicos federais em

Florianópolis (SC)

finalidade específica das licitações públicas, como o desenvolvimento nacional sustentável. ${ }^{7}$

Desde a Constituição de 1988, o texto constitucional do inciso XXI do art. 37 dispõe que, à exceção dos casos especificados na lei, "[...] as obras, serviços, compras e alienações serão contratados mediante processo de licitação pública que assegure igualdade de condições a todos os concorrentes [...]" (BRASIL, 1988). A parte final do inciso ainda reforça que a lei somente poderá exigir qualificações técnica e econômica indispensáveis à garantia do cumprimento das obrigações.

A disciplina infraconstitucional desta prescrição normativa fundamental veio consolidada pela Lei n. 8.666/1993. Sobre o tema, a redação original do art. 3 - do referido diploma legal previa como finalidade da licitação a garantia da isonomia e a seleção da proposta mais vantajosa, sem mencionar qualquer disposição relacionada à questão do desenvolvimento sustentável:

Art. 3ำ A licitação destina-se a garantir a observância do princípio constitucional da isonomia e a selecionar a proposta mais vantajosa para a Administração e será processada e julgada em estrita conformidade com os princípios básicos da legalidade, da impessoalidade, da moralidade, da igualdade, da publicidade, da probidade administrativa, da vinculação ao instrumento convocatório, do julgamento objetivo e dos que lhes são correlatos (BRASIL, 1993).

A busca pela proposta mais vantajosa conduzia geralmente à escolha do menor preço, ou de outros quesitos previstos no próprio ordenamento jurídico, como a técnica, ou a conjugação de preço e técnica (tipos de licitação). Conforme esclarece Érica Miranda dos Santos Requi, "não havia, portanto, menção expressa à garantia do desenvolvimento nacional sustentável, motivo pelo qual a inclusão de critérios de sustentabilidade nas contratações públicas era questionada" (2012, p. 379).

Ainda que desde a Constituição de 1988 existisse um arcabouço principiológico de proteção ao meio ambiente, além dos diversos tratados

${ }^{7}$ Sobre o tema do desenvolvimento, ver: BERCOVICI, 2005; HACHEM, 2013. 
internacionais ratificados pelo Brasil, a justificação de inclusão de critérios de sustentabilidade nas licitações carecia de uma norma legal explícita.

Com a edição da Medida Provisória n. 495/2010, posteriormente convertida da Lei n. 12.349/2010 (BRASIL, 2010), restou incluída como finalidade da licitação a busca pelo desenvolvimento nacional sustentável. Referida legislação modificou a redação do art. 30 da Lei 8.666/1993, de modo a incluir a sustentabilidade ambiental como quesito de julgamento das propostas.

A licitação agora cumpre três finalidades legais: garantia da isonomia de tratamento entre os licitantes; seleção da proposta mais vantajosa; e, promoção do desenvolvimento nacional sustentável. A valoração do preço precisa agora incluir os custos indiretos, de forma que, "[...] antes de licitar, não se podem mais ignorar, candidamente, os custos ambientais, sociais e econômicos de cada escolha administrativa" (FREITAS, 2011, p. 17).

Essa trinca de finalidades indica a aplicação conjugada de interesses, de maneira a harmonizar preço com sustentabilidade. Portanto, sobre os critérios ecológicos e sociais, a Administração Pública deve, na mesma proporção, promover os benefícios à sociedade e mitigar os impactos ambientais, por meio da estipulação de critérios de sustentabilidade a serem observados pelos fornecedores que desejam participar do procedimento licitatório (SOUZA, 215).

Deste novo desiderato licitatório surge a definição de licitações sustentáveis, aquelas que levam em conta a sustentabilidade ambiental dos produtos e processos a ela relacionados. De acordo com Rosa Maria Meneguzzi, pode-se entendê-las como "[...] um processo por meio do qual as organizações [...] valorizam os custos efetivos [...], buscando gerar benefícios à sociedade e à economia e reduzir os danos ao ambiente natural" (2015, p. 24).

Com efeito, a proposta mais vantajosa não é aquela que atenda apenas a dimensão financeira (preço direto), mas sim a resultante da conjugação dos parâmetros de economia e sustentabilidade ambiental (preço direto e indireto). A toda evidência, “[...] o critério apenas econômico tendo em vista o menor preço poderia levar o próprio Estado, ao não analisar os critérios ambientais e sociais, a afrontar sua própria legislação e, até mesmo, utilizar de forma irresponsável os seus recursos financeiros" (AMARAL, 2015, p. 07). 
Licitações públicas e sustentabilidade: uma análise de aplicação de critérios ambientais nas compras dos órgãos públicos federais em

Florianópolis (SC)

Até a expressa inclusão dessa nova e alvissareira finalidade, a proposta mais vantajosa para a Administração Pública indubitavelmente decorreria do viés econômico. Ainda que a licitação não fosse do tipo menor preço, a proposta mais vantajosa seria aquela cuja relação custo-benefício se mostrasse melhor para a Administração, levando em conta especificamente aspectos econômicos. Atualmente, incumbe reconhecer que a proposta mais vantajosa será aquela que apresentar a melhor relação ponderada de eficiência, tanto diretamente sobre aquela respectiva contratação, como também os benefícios indiretos, mediatos e de longo prazo que a proposta vencedora proporcionará ao desenvolvimento sustentável (FERREIRA, 2012).

Segundo Hamilton Antonio Coelho (2013, p. 58), hodiernamente o procedimento licitatório que busca somente o menor preço não atende mais aos anseios da sociedade contemporânea, nem das futuras gerações. Ao Poder Público não basta somente patrocinar a sustentabilidade, ele deve também ser eficiente e ecológico por ocasião das contratações públicas, procurando a simbiose entre o menor preço e a geração de menos resíduos e impactos ambientais. Em síntese, além de ecoeficiente o Estado deve ser ecoconsumidor.

\subsection{A Lei n. $12.349 / 2010$ e a Instrução Normativa n. $01 / 2010$ da SLTI/MPOG}

A conversão da Medida Provisória n. 495/2010 na Lei n. 12.349/2010 instituiu o marco legal das licitações sustentáveis. Indubitavelmente, seu texto possui um caráter inovador, porém como a maioria das leis, apenas demarcou as linhas gerais da promoção do desenvolvimento sustentável por meio das licitações, cabendo às normas regulamentares a pormenorização das respectivas diretrizes do procedimento licitatório.

Com efeito, antes mesmo da edição da Medida Provisória n. 495/2010, convertida na Lei n. 12.349/2010 (BRASIL, 2010), no âmbito federal o Ministério do Planejamento, Orçamento e Gestão (MPOG), na figura da Secretaria de Logística e Tecnologia da Informação do Ministério do Planejamento (SLTI), havia editado a Instrução Normativa n. 01, de 19 de janeiro de 2010 (BRASIL, 2010), a dispor sobre os critérios de sustentabilidade na aquisição de bens, contratação de serviços ou obras pela 
Administração Pública federal direta autárquica e fundacional. Tal iniciativa precursora teve como fundamentos os mandamentos e princípios constitucionais que tratam do dever do Estado na promoção da preservação ambiental e da sustentabilidade.

Outro instrumento legal essencial na disciplina das licitações sustentáveis é o Decreto n. 7.746/2012 (BRASIL, 2012), que regulamenta o art. 3ㅇ da Lei n. 8.666/1993, na redação trazida pela Lei n. 12.349/2010. O referido diploma estabelece critérios, práticas e diretrizes para a promoção do desenvolvimento nacional sustentável nas contratações da Administração Pública federal e institui a Comissão Interministerial de Sustentabilidade na Administração Pública - CISAP, de forma a consolidar e ampliar o Programa de Contratações Sustentáveis do Ministério do Planejamento, Orçamento e Gestão (MPOG).

Atualmente, ainda não há um modelo padronizado federal para a especificação detalhada de materiais e serviços sustentáveis. Observa-se, entretanto, a edição, setorizada por órgãos públicos, de guias de práticas de contratações sustentáveis, que também cumprem a função de complementar os dispositivos legais mencionados, dentre os quais cabe citar - Guia Prático de Licitações Sustentáveis da Consultoria Jurídica da União no Estado de São Paulo - AGU (Advocacia-Geral da União, 2013), e o banco de dados de boas práticas de licitações sustentáveis disponível no sítio da internet de compras governamentais do Governo Federal, que indicam como inserir, nos termos de referência dos editais, critérios sustentáveis sobre diversos tipos de materiais.

Em síntese, cumpre ressaltar que o paradigma das licitações sustentáveis possui base legal e regulamentar consolidada. No entanto, ainda que não editados tais instrumentos normativos, esse marco finalístico encontra fundamento principiológico na própria proteção constitucional do meio ambiental pelo Estado, conforme se extrai diretamente da Constituição de 1988.

\section{Sobre o marco normativo constitucional da proteção ao meio ambiente pelo Estado e o paradigma da sustentabilidade}

Conforme já adiantado, o movimento ecológico mundial, fruto da degradação ambiental vivida pela sociedade a partir de meados do século XX, teve como um dos marcos iniciais a Conferência das Nações Unidas sobre o Meio Ambiente Humano, também conhecida como Conferência de 
Licitações públicas e sustentabilidade: uma análise de aplicação de critérios ambientais nas compras dos órgãos públicos federais em

Estocolmo, em 1972. Este marco supranacional “[...] deu origem ao inovador e imprescindível paradigma [...] voltado ao desenvolvimento socioeconômico arquitetado por meio de ações ambientais responsavelmente ideadas" (COELHO, 2013, p. 24).

Desde aquele momento histórico, diversas nações democráticas alçaram à dimensão constitucional a primazia pelo zelo ao meio ambiente, bem como preceitos destinados à tomada de decisões responsáveis na utilização de matérias-primas naturais. Inclusive, o Brasil seguiu esse posicionamento de forma a contemplar dispositivos com firme orientação normativa sobre a conduta da sustentabilidade ambiental pela Sociedade e pelo Estado (DERANI, 2008).

O art. 225 da Constituição de 1988 assenta o direito ao meio ambiente ecologicamente equilibrado e impõe ao Poder Público e à coletividade em geral o dever de defendê-lo e preservá-lo para as presentes e futuras gerações.

Cumpre frisar que o dever de preservação ambiental pela Administração Pública, como consumidora de bens, serviços e obras, sempre esteve constitucional e legalmente garantido, mesmo quando silente o art. 3o da Lei n. 8.666/1993 sobre a garantia ao desenvolvimento nacional sustentável como finalidade da licitação. Vale recordar que, conforme o art. 2ㅇ da Lei n. 6.938/1981 (BRASIL, 1981), que institui a Política Nacional do Meio Ambiente, recepcionada pela Constituição de 1988, é dever da Administração Pública atuar na preservação e melhoria da qualidade ambiental, visando o desenvolvimento socioeconômico e a proteção da dignidade da vida humana.

Sobre a questão da competência dos entes federados sobre essa matéria, é possível observar a atuação conjunta na questão ambiental, uma espécie de missão conjugada de todo o Poder Público em prol da proteção ambiental. Conforme o inciso VI do art. 23 da Constituição de 1988, "É competência comum da União, dos Estados, do Distrito Federal e dos Municípios: proteger o meio ambiente e combater a poluição em qualquer de suas formas" (BRASIL, 1988). Já o inciso VI do art. 24 da Constituição de 1988, preceitua que "Compete à União, aos Estados e ao Distrito Federal legislar concorrentemente sobre: florestas, caça, pesca, fauna, conservação da natureza, defesa do solo e dos recursos naturais, proteção do meio ambiente e controle da poluição" (BRASIL, 1988). 
Em relação à regulação da ordem econômica, os comandos constitucionais convergem para uma atuação de defesa do meio ambiente de maneira a assegurar o desenvolvimento nacional equilibrado com uma existência digna. O inciso VI do art. 170 da Constituição de 1988 prescreve que a ordem econômica deve observar o princípio da "[...] defesa do meio ambiente, inclusive mediante tratamento diferenciado conforme o impacto ambiental dos produtos e serviços e de seus processos de elaboração e prestação" (BRASIL, 1988). Já o § 1ำ do art. 174 da Constituição de 1988 prevê que "A lei estabelecerá as diretrizes e bases do planejamento do desenvolvimento nacional equilibrado, o qual incorporará e compatibilizará os planos nacionais e regionais de desenvolvimento" (BRASIL, 1988).

Retornado ao art. 225 da Constituição de 1988, tal dispositivo constitucional prevê nos seus incisos alguns poderes-deveres ao Poder Público como a exigência de estudo de impacto ambiental na realização de obras ou atividades potencialmente degradantes; o controle da produção, comercialização, e emprego de técnicas, métodos e substâncias que comportem risco para a vida, a qualidade de vida e o meio ambiente; a promoção da educação ambiental em todos os níveis; além da proteção da fauna e a flora, sendo vedadas as práticas que coloquem em risco sua função ecológica (GARCIA; RIBEIRO, 2012).

Estas previsões constitucionais coadunam com a Política Nacional do Meio Ambiente (PNMA), de que trata a Lei n. 6.938/1981, e deram sustentação ao art. 12 da Lei n. 8.666/1993, ao dispor que, nos projetos básico e executivo de obras e serviços, são considerados vários requisitos, entre os quais o de impacto ambiental.

Inegavelmente, tal marco constitucional sobre a preservação ambiental pretende adequar a produção e o consumo às exigências de sustentabilidade do meio ambiente, no âmbito público e privado. Como defende Hamilton Antonio Coelho, "[...] a intenção do legislador constituinte, ao redigir referidos comandos, foi de traçar viés ecológico para a produção e o consumo, seja este estatal ou não" (2013, p. 41).

De fato, ainda que não existisse previsão expressa na Lei n. 8.666/1993, desde a instituição da Política Nacional do Meio Ambiente e, mais ainda, após a promulgação da atual Constituição da República, a Administração Pública tem o dever de promover contratações públicas que garantam a fiel observância dos princípios $^{8}$ inerentes ao desenvolvimento

${ }^{8}$ Para uma análise crítica sobre a teoria dos princípios, ver: CRISTÓVAM, 2016, p. 258-271. 
sustentável, quer pela sua condição de consumidor de bens, serviços e obras, quer pela sua condição de agente público responsável pela regulação da ordem econômica.

Nesse panorama, pode-se afirmar a existência de um autêntico modelo de Estado socioambiental de direito, de forma que os princípios que regem o desenvolvimento ambiental e socialmente sustentável devem orientar e vincular as condutas públicas e privadas no seu trânsito pela ordem econômica. ${ }^{9}$

Não é correto afirmar que a sustentabilidade ambiental insculpida no ordenamento constitucional teria incidência apenas nas questões diretamente relacionadas à proteção ecológica. De fato, é também plenamente aplicável no regime de licitações em geral, como "[...] instrumento estatal indispensável à proteção e defesa do meio ambiente, cujo propósito é o de minimizar impactos ecológicos negativos, incluindo-se os ocasionados pelo consumo do próprio governo" (COELHO, 2013, p. 42).

Nesse mesmo sentido, sustenta Rafael Lopes Torres (2011, p. 07):

A realização das chamadas licitações sustentáveis se insere no contexto acima e deve ser um dos instrumentos de concretização do direito expresso no caput do art. 225 da Constituição Federal. Nesse sentido, não se vislumbra, pela inserção de critérios ambientais nos editais de licitação, qualquer conflito com o art. 37, inciso XXI, da CF/88, que estabelece igualdade de condições a todos os concorrentes nas licitações públicas. A igualdade ou a isonomia consiste em tratar de forma igual os iguais e de forma desigual os desiguais, na medida de sua desigualdade.

É justamente no procedimento licitatório que os órgãos públicos têm a oportunidade de materializar a tutela do meio ambiente, ao escolher produtos, mercadorias e serviços fabricados, fornecidos ou prestados de forma ecologicamente inteligente, de forma a cumprir, assim, os princípios, normas e regras de regência na defesa do meio ambiente e da sustentabilidade. Imprescindível, pois, a observância dos princípios de

\footnotetext{
${ }^{9}$ O Estado socioambiental de direito é aquele em cuja ordem constitucional da proteção ambiental ocupa lugar e hierarquia fundamental, resultando que, na promoção dos direitos prestacionais, a preservação das condições ambientais passa a balizar as ações estatais e as políticas públicas. Sobre o tema, ver: LEITE, 2015.
} 
sustentabilidade ambiental, de forma a garantir uma interpretação harmônica de proteção ao conjunto de bens tutelados pela Constituição de 1988.

\section{A função fomentadora do Estado nas licitações públicas e o paradigma da sustentabilidade}

Conforme já adiantado, o sítio da internet de compras sustentáveis do Governo Federal indica que o poder de compra do Estado representa pelo menos $10 \%$ do PIB brasileiro, sendo que esse percentual pode chegar a $15 \%$. As compras governamentais afetam setores importantes da economia e têm um grande poder de influenciar os rumos do mercado. Cabe ao governo, como grande comprador, induzir e estimular o setor produtivo a atuar na esteira do que prescreve o Guia de Contratações Sustentáveis da Justiça do Trabalho: "[...] resulta em melhoria do bem-estar humano e equidade social, ao mesmo tempo em que gera valor para a Natureza, reduzindo significativamente os impactos e riscos sociais e ambientais e a demanda sobre recursos escassos do ecossistema e da sociedade" (CONSELHO SUPERIOR DA JUSTIÇA DO TRABALHO, 2014).

De acordo com Sidney Bittencourt (2014), tal realidade permite afirmar que o impacto econômico causado pelas compras e contratações realizadas pelo Governo e seu poder de indução do mercado constituem fatores chave para a implementação de compras públicas sustentáveis. Segundo dispõe o Guia de Compras Públicas Sustentáveis para a Administração Federal:

[...] as autoridades públicas, como consumidores de grande escala, podem incentivar a inovação, estimular a competição na indústria, garantindo, aos produtores, retornos pelo melhor desempenho ambiental de seus produtos, através da demanda do mercado ou de incentivos concretos (FORESTI; SANTOS; SANTOS NETO, 2015).

Por certo, de forma isolada, ao adquirir produtos ou contratar serviços sustentáveis, um órgão não consegue modificar o comportamento do mercado. Entretanto, várias autoridades públicas, que adotam essa política e combinam sua capacidade e poder de compra podem obter resultados concretos. Essa sistemática exerce um papel relevante uma vez que a 
escolha pela sustentabilidade tem mudado consideravelmente a estrutura de mercado.

Destaca-se que o impacto econômico desse poder de compra no mercado resulta em uma mudança de paradigma nas compras públicas. Antes, o paradigma era a eficiência - comprar mais rápido pelo menor custo possível. Hoje, a nova política deve considerar o uso do poder de compra do Estado, em aquisições de segmentos estratégicos e relevantes para o desenvolvimento econômico e social sustentável (BETIOL, 2012).

O novo paradigma das contratações públicas é a combinação da eficiência com o uso do poder de compra do Estado direcionado ao fomento à sustentabilidade ambiental. A contratação pública adquire uma condição de instrumento de fomento público e regulador da ordem econômica.

Para Érica Miranda dos Santos Requi (2012), os Governos exercem um papel indutor na economia ao criar leis, incentivos, impostos, mas também, por serem os consumidores mais ativos do mercado. Às autoridades públicas é dada a responsabilidade para a gestão da coisa pública com eficiência e, ao mesmo tempo, a busca pela melhoria da qualidade de vida dos cidadãos.

Com efeito, se a maioria dos compradores públicos optar por produtos mais sustentáveis, uma demanda maior estimulará uma oferta maior, que conduzirá por sua vez a um preço mais competitivo. Aquisições públicas podem ajudar a criar um grande mercado para negócios sustentáveis, aumentando as margens de lucro dos produtores por meio de economias de escala e reduzindo seus riscos. Além disso, as autoridades públicas, atores poderosos no mercado, podem incentivar a inovação e, consequentemente, estimular a competição da indústria, garantindo aos produtores recompensas pelo melhor desempenho ambiental de seus produtos, por meio da demanda do mercado de incentivos concretos (COELHO, 2013).

De acordo com o Relatório de Diretrizes aos Planos de Gestão de Logística Sustentável do Ministério do Planejamento Orçamento e Gestão, a empresa é o motor da inovação, mas os Governos precisam fornecer sinais claros e estáveis ao mercado, operando em parceria para fazer isso acontecer. As tecnologias podem ser caras e os investimentos precisam ser compensados e incentivados. Os Governos podem tornar esses investimentos mais viáveis, por meio de instrumentos econômicos e fiscais.

Otimizar processos internos e promover um desenvolvimento mais sustentável por meio do poder de compra governamental é uma questão 
estratégica, que além do potencial de fomentar um mercado inovador e de menor impacto, aborda questões emergentes e urgentes como: a mudança climática; o consumo excessivo que não considera a capacidade de suporte do planeta; a busca por menor desigualdade socioeconômica; e a melhoria da qualidade de vida em um mundo cada vez mais urbanizado.

Com razão, Daniel Ferreira entende que a busca pelo desenvolvimento nacional sustentável nas contratações públicas é, em verdade, o cumprimento da "função social" da licitação, a qual deve ser reconhecida como aspecto inerente "[...] ao regular exercício da função administrativa, que tem por escopo a satisfação concreta dos interesses públicos, como previstos na Constituição e nas leis, e em regime de concomitância, sempre que possível, em qualquer estado democrático e republicano, tal qual o Brasil" (2010, p. 50).

A contratação pública não pode mais ser vista unicamente como processo administrativo para a contratação de bens, serviços e obras, passando a figurar como instrumento de fomento público, de modo a aplicar o poder de compra do Estado na forma de ferramenta para a regulação da ordem econômica. Nessa medida, portanto, deve promover o desenvolvimento nacional sustentável e implementar políticas ambientais e sociais. Conforme consta nas linhas gerais da Declaração Final da Conferência das Nações Unidas sobre Desenvolvimento Sustentável (Rio + 20) em 2012: "As compras públicas são um instrumento fundamental para se avançar na construção de uma economia mais verde e inclusiva" (ONU, Rio $+20,2012)$.

\section{A aplicação dos critérios de sustentabilidade ambiental por órgãos públicos federais em Florianópolis (SC) - Biênio 2015/2016}

Passada a análise sobre o novo quadro normativo relacionado aos critérios de sustentabilidade ambiental nas licitações públicas, passa-se ao estudo de campo sobre o tema, no sentido de procurar observar se essas modificações normativas acabaram por refletir na prática administrativa, ou seja, na contratação de materiais e serviços sustentáveis. Para tanto, foi realizado levantamento sobre a adoção de critérios de sustentabilidade ambiental por órgãos públicos federais localizados em Florianópolis (SC), no biênio 2015/2016. O método de abordagem utilizado foi análise de conteúdo. $O$ procedimento utilizado foi o estudo de caso, a partir da análise 
Licitações públicas e sustentabilidade: uma análise de aplicação de critérios ambientais nas compras dos órgãos públicos federais em

de 50 (cinquenta) pregões eletrônicos onde se verificou a adoção de critérios de sustentabilidade ambiental pelos referidos órgãos públicos federais.

Para chegar a uma amostra representativa foram selecionados 13 (treze) órgãos públicos federais sediados em Florianópolis (SC), que refletem diversas necessidades de materiais e serviços. Ainda, para fins de sistematizar a coleta, foram selecionadas 6 (seis) classes de materiais e serviços comuns que são adquiridas pela maioria dos órgãos públicos: material de limpeza e higiene; serviço de limpeza e/ou coleta de resíduos; materiais de consumo diversos; gêneros de alimentação; material permanente; e material para manutenção predial.

Atualmente, além dos marcos legais e regulamentares sobre as contratações sustentáveis, já existem guias práticos de confecção de editais de licitação sustentáveis que auxiliam na descrição do item a ser licitado. Como parâmetro de análise dos 50 (cinquenta) editais selecionados foram observadas as orientações dos já referidos Guia de Contratações Sustentáveis da Justiça do Trabalho e Guia Prático de Licitações Sustentáveis da Consultoria Jurídica da União. Tais manuais serviram de base para a análise dos critérios ambientais nos editais selecionados.

\subsection{Análise quantitativa dos critérios sustentáveis}

Conforme demonstra o quadro abaixo, da análise quantitativa dos 50 (cinquenta) editais selecionados retira-se um percentual de inserção de sustentabilidade em $47,74 \%$ dos casos. Apesar de uma amostra limitada, isso permite constatar uma baixa porcentagem de aproveitamento do potencial sustentável, porquanto sequer chega a $50 \%$ dos casos pesquisados.

\begin{tabular}{|l|l|l|l|l|}
\hline \multirow{2}{*}{ Classe de materiais/serviço } & \multicolumn{3}{|c|}{$\begin{array}{c}\text { Contabilização da } \\
\text { inserção ou não dos } \\
\text { critérios sustentáveis }\end{array}$} & $\begin{array}{c}\text { Porcentagem de } \\
\text { inserção de } \\
\text { sustentabilidade }\end{array}$ \\
\cline { 2 - 4 } & Sim & Não & Total & \\
\hline Materiais de limpeza e higiene & 12 & 23 & 35 & $34,29 \%$ \\
\hline $\begin{array}{l}\text { Serviço de limpeza e/ou coleta de } \\
\text { resíduos }\end{array}$ & 19 & 12 & 31 & $61,29 \%$ \\
\hline
\end{tabular}




\begin{tabular}{|l|l|l|l|l|}
\hline Materiais de consumo diversos & 16 & 13 & 29 & $55,17 \%$ \\
\hline Gêneros de alimentação & 02 & 14 & 16 & $12,50 \%$ \\
\hline Materiais permanentes & 19 & 13 & 32 & $59,38 \%$ \\
\hline $\begin{array}{l}\text { Materiais para manutenção predial } \\
\text { (lâmpadas, luminárias e reatores) }\end{array}$ & 06 & 06 & 12 & $50,00 \%$ \\
\hline Total & $\mathbf{7 4}$ & $\mathbf{8 1}$ & $\mathbf{1 5 5}$ & $\mathbf{4 7 , 7 4 \%}$ \\
\hline
\end{tabular}

Dentro das classes de materiais/serviço interessa observar a pequena porcentagem de $12,50 \%$ na aquisição de gêneros de alimentação, bem como o baixo valor de $34,29 \%$ nos materiais de limpeza e higiene.

As outras classes (serviço de limpeza e/ou coleta de resíduos; materiais de consumo diversos; materiais permanentes; e materiais para manutenção predial) mantiveram uma média de 65,29\%.

\subsection{Análise qualitativa dos critérios sustentáveis}

$\mathrm{Na}$ mesma senda, a forma de inserção dos critérios de sustentabilidade foi analisada a fim de verificar qual a maneira mais utilizada nos editais de pregão eletrônico coletados. Naqueles editais que contemplaram critérios sustentáveis, observou-se que tal formato é livre, não havendo uma forma definida. Grande parcela desses certames licitatórios preferiu utilizar um texto padrão no meio do edital contemplando alguns critérios sustentáveis, de acordo com a Instrução Normativa no 01/2010 do SLTI/MPOG. Esse texto constou genericamente em muitos editais verificados, mesmo que os procedimentos não contemplassem aquisições que se enquadrassem nessas orientações. Ao que parece, isso indica se tratar apenas de um formulário padrão.

Muito possivelmente, haveria maior eficácia com a inserção individual dos critérios de sustentabilidade na própria descrição do objeto licitado, uma vez que cada um possui sua especificidade. Tal prática foi observada em alguns editais licitatórios, fato que indica uma maior aderência substancial do respectivo órgão público ao modelo de licitação sustentável, além da própria efetividade do atendimento aos quesitos por parte dos fornecedores. 
Entre os principais fatores a ocasionar esse aparente aproveitamento reduzido cabe destacar a resistência por parte dos servidores responsáveis pelas compras públicas em adequarem os editais de licitação às novas tendências da sustentabilidade. Isso pode resultar do próprio receio de impugnações e recursos dos fornecedores no processo licitatório, além da falta de fornecedores sensíveis às demandas ambientais, o que muitas vezes acarreta lacunas nas pesquisas de mercado, fase preparatória que pode frustrar a licitação.

Outro fator digno de consideração se refere à cobrança de agilidade nos processos licitatórios pelo próprio órgão licitante. Por vezes, a licitação sustentável acaba por resultar em um processo mais lento, uma vez que exige maior atenção e trabalho nas fases de descrição do objeto, cotação de preços e análise de amostras do material e/ou serviço licitados etc. As exigências por agilidade podem desestimular a aplicação do modelo de licitações sustentáveis. Em verdade, esse modelo reclama o entendimento de toda a rede de agentes estatais, em uma visão sistêmica do processo, de modo a dar suporte às ações dos responsáveis pelas aquisições, inclusive os gestores públicos.

Há que se considerar, ainda, a situação de possível incipiência na capacitação aos agentes públicos. Ainda que o portal de compras sustentáveis, disponível na rede mundial de computadores, represente uma excelente ferramenta de consulta, a licitação sustentável exige preparo, conhecimento e constante aprimoramento dos agentes públicos para o regular desenvolvimento do procedimento licitatório sustentável.

Em síntese, constata-se que o quesito qualitativo dos critérios sustentáveis foi explorado de maneira tímida nos editais de pregão coletados. A maioria preferiu um texto padrão no corpo do edital. O maior impacto positivo desses critérios viria com um maior detalhamento dos quesitos de sustentabilidade, preferencialmente na própria especificação de cada objeto, o que tornaria a licitação sustentável mais efetiva, inclusive por facilitar aos licitantes observar com clareza os requisitos necessários.

\section{Considerações finais}


A finalidade inicial das licitações, segundo o texto original da Lei n. $8.666 / 1993$, limitada à garantia da isonomia e alcance da proposta mais vantajosa, geralmente submetida ao critério econômico do menor preço, ganha um novo e alvissareiro colorido com o advento da Lei n. 12.349/2010, que alterou a Lei n. 8.666/1993, e do Decreto n. 7.746/2012, passando a indicar uma nova finalidade que é o desenvolvimento nacional sustentável, mediante a utilização de critérios sustentáveis.

Essa nova finalidade das compras públicas deve ser conjugada com as finalidades originais da licitação, cabendo uma atuação ponderada de maneira a harmonizar preço com sustentabilidade. Em verdade, a proposta mais vantajosa será aquela que melhor atenda aos objetivos da licitação e ao interesse público, que em síntese é a contratação sustentável com o menor preço.

Cumpre ressaltar que, embora não existisse previsão expressa na redação original da Lei n. 8.666/1993, desde a instituição da Política Nacional do Meio Ambiente e, mais ainda, após a promulgação da Constituição de 1988, a Administração Pública sempre teve o dever de promover contratações públicas capazes de garantir a fiel observância dos princípios inerentes ao desenvolvimento sustentável.

Sobre a aderência da Administração Pública na questão da contratação sustentável, o estudo de caso sobre a adoção de critérios de sustentabilidade ambiental limitou-se aos órgãos públicos federais localizados em Florianópolis (SC), no biênio 2015/2016, a partir da coleta e análise quantitativa e qualitativa de 50 (cinquenta) editais de licitações, a fim de verificar a especificação de cada material ou serviço constante do termo de referência, no que toca à inserção de critérios de sustentabilidade.

A pesquisa leva à conclusão que a referida inserção foi realizada de maneira tímida. Do ponto de vista quantitativo, correspondeu a apenas $47,74 \%$ do potencial que poderia ser explorado, sendo que qualitativamente a maioria dos critérios foi inserida de maneira genérica nos editais, carecendo de uma individualização na descrição de cada objeto.

O Governo é o indutor dessa nova perspectiva, porém precisa superar os entraves que ainda permeiam a atividade licitatória. Entre as possíveis razões para o baixo grau de adesão às licitações sustentáveis por parte da Administração Pública indica-se o receio de impugnações e recursos no processo licitatório; a cobrança por agilidade dos processos de contratações 
Licitações públicas e sustentabilidade: uma análise de aplicação de critérios ambientais nas compras dos órgãos públicos federais em

Florianópolis (SC)

pelos respectivos gestores; e a insuficiente qualificação dos respectivos servidores para a atuação em matéria de licitações sustentáveis.

O modelo de licitações sustentáveis é um processo necessário e irreversível. O Estado tem enorme responsabilidade na indução de uma cultura de sustentabilidade, e está a demonstrar crescente comprometimento normativo, com a edição de instrumentos legais e infralegais. Cabe agora uma maior atuação governamental de efetiva aplicação de critérios de efetivação do desenvolvimento nacional sustentável, mormente pela via das aquisições sustentáveis.

\section{Referências}

AGU - ADVOCACIA-GERAL DA UNIÃO. Guia prático de licitações sustentáveis da Consultoria Jurídica da União no Estado de São Paulo - AGU, São Paulo, 2013.

AMARAL, Daiane Acosta et al. Licitações Sustentáveis. Revista Científica Semana Acadêmica, n. 70, jul. 2015. Disponível em: <http://semanaacademica.org.br/artigo/licitacoes-sustentaveis>. Acesso em: 10 ago. 2017.

BERCOVICI, Gilberto. Constituição econômica e desenvolvimento: uma leitura a partir da Constituição de 1988. São Paulo: Malheiros, 2005.

BETIOL, Luciana Stocco et al. Compra sustentável: a força do consumo público e empresarial para uma economia verde e inclusiva. 1. ed. São Paulo: Programa Gestão Pública e Cidadania, 2012. Disponível em: <http://www.cetem.gov.br/sustentavel/sustentabilidade/pdf/Compras_Publicas_Suste ntaveis/LIVRO_Compra_Sustentavel.pdf>. Acesso em: 10 ago. 2017.

BITTENCOURT, Sidney. Licitações sustentáveis: o uso do poder de compra do Estado fomentando o desenvolvimento nacional sustentável. Belo Horizonte: Del Rey, 2014.

BRASIL. Constituição da República Federativa do Brasil de 1988. Disponível em: <http://www.planalto.gov.br/ccivil_03/Constituicao/ConstituicaoCompilado.htm>.

Acesso em: 10 ago. 2017.

BRASIL. Decreto n. 7.746, de 05 de junho de 2012. Regulamenta o art. 3 da Lei no 8.666, de 21 de junho de 1993, para estabelecer critérios, práticas e diretrizes para a promoção do desenvolvimento nacional sustentável nas contratações realizadas pela Administração Pública federal, e institui a Comissão Interministerial de Sustentabilidade na Administração Pública - CISAP. Disponível em: <http://www.planalto.gov.br/ccivil_03/_ato2011-2014/2012/decreto/d7746.htm>. Acesso em: 10 ago. 2017. 
BRASIL. Instrução Normativa n. 01, de 19 de janeiro de 2010. Ministério do Planejamento, Orçamento e Gestão. Dispõe sobre os critérios de sustentabilidade ambiental na aquisição de bens, contratação de serviços ou obras pela Administração Pública Federal direta, autárquica e fundacional e dá outras providências. Disponível em: <http://www.comprasnet.gov.br/legislacao/legislacaoDetalhe.asp?ctdCod=295>. Acesso em: 10 ago. 2017.

BRASIL. Lei $\mathbf{n} . \mathbf{6 . 9 3 8}$, de 31 de agosto de 1981 . Dispõe sobre a Política Nacional do Meio Ambiente, seus fins e mecanismos de formulação e aplicação, e dá outras providências. Disponível em: <http://www.planalto.gov.br/ccivil_03/leis/L6938compilada.htm>. Acesso em: 10 ago. 2017.

BRASIL. Lei n. 8.666, de 21 de junho de 1993. Regulamenta o artigo 37, inciso XXI, da Constituição Federal, institui normas para licitações e contratos da Administração Pública e dá outras providências. Disponível em: <http://www.planalto.gov.br/ccivil_03/leis/L8666cons.htm>. Acesso em: 10 ago. 2017.

BRASIL. Lei n. 12.349, de 15 de dezembro de 2010. Altera a Lei n. 8.666, de 21 de junho de 1993. Disponível em: <http://www.planalto.gov.br/ccivil_03/_ato20072010/2010/Mpv/495.htm>. Acesso em: 10 ago. 2017.

BRASIL. Medida Provisória n. 495, de 19 de julho de 2010. Altera a Lei n. 8.666, de 21 de junho de 1993. Disponível em: <http://www.planalto.gov.br/ccivil_03/_ato20072010/2010/Mpv/495.htm>. Acesso em: 10 ago. 2017.

COELHO, Hamilton Antonio. Responsabilidade ambiental na licitação: sustentabilidade nas contratações e compras do governo. 187 f. Dissertação (Mestrado em Direito) Escola Superior Dom Helder Câmara, Belo Horizonte, 2013.

COMPRAS GOVERNAMENTAIS. Desenvolvido pelo Ministério do Planejamento, Desenvolvimento e Gestão. Disponibiliza serviços de compras governamentais aos licitantes e ao Governo Federal. Disponível em: <http://www.comprasgovernamentais.gov.br/>. Acesso em: 10 ago. 2017.

CONSELHO SUPERIOR DA JUSTIÇA DO TRABALHO. Guia de contratações sustentáveis da Justiça do Trabalho, Brasília, 2014.

CRISTÓVAM, José Sérgio da Silva. Administração Pública democrática e supremacia do interesse público: novo regime jurídico-administrativo e seus princípios constitucionais estruturantes. Curitiba: Juruá, 2015.

CRISTÓVAM, José Sérgio da Silva. Princípios constitucionais: razoabilidade, proporcionalidade e argumentação jurídica. 2. ed. Curitiba: Juruá, 2016.

DERANI, Cristiane. Direito ambiental econômico. São Paulo: Saraiva, 2008.

FERREIRA, Daniel. A licitação pública no Brasil e sua nova finalidade legal: a promoção do desenvolvimento nacional sustentável. Belo Horizonte: Fórum, 2012. 
Licitações públicas e sustentabilidade: uma análise de aplicação de critérios ambientais nas compras dos órgãos públicos federais em

Florianópolis (SC)

FERREIRA, Daniel. Função social da licitação pública: o desenvolvimento nacional sustentável (no e do Brasil, antes e depois da MP no 495/2010). Fórum de Contratação e Gestão Pública, v. 107, p. 49-64, 2010.

FINGER, Ana Claudia; QUETES, Regeane Bransin. Licitações e contratos administrativos sustentáveis como um instrumento de concretização da supremacia do interesse público. A\&C - Revista de Direito Administrativo \& Constitucional, Belo Horizonte, ano 14, n. 57, p. 105-131, jul./set. 2014.

FORESTI, Loreni Fracasso; SANTOS, Rogério Santanna dos; SANTOS NETO, Ana Maria Vieira dos. Guia de compras públicas sustentáveis para administração federal. Disponível em: <https://www.unila.edu.br/sites/default/files/files/cartilha-comprassustentaveis.pdf>. Acesso em: 10 ago. 2017.

FORTINI, Cristiana; MOTTA, Fabrício. Corrupção nas licitações e contratações públicas: sinais de alerta segundo a Transparência Internacional. A\&C - Revista de Direito Administrativo \& Constitucional, Belo Horizonte, ano 16, n. 64, p. 93-113, abr./jun. 2016.

FREITAS, Juarez. Licitações e Sustentabilidade: Ponderação obrigatória dos custos e benefícios sociais, ambientais e econômicos. Revista Interesse Público, Belo Horizonte, ano 13, n. 70, p. 15-35, nov./dez. 2011.

FREITAS, Juarez. Sustentabilidade: direito ao futuro. 3. ed. Belo Horizonte: Fórum, 2016.

GARCIA, Flavio Amaral; RIBEIRO, Leonardo Coelho. Licitações públicas sustentáveis. Revista de Direito Administrativo, Rio de Janeiro, v. 260, p. 231-254, mai./ago. 2012.

HACHEM, Daniel Wunder. A maximização dos direitos fundamentais econômicos e sociais pela via administrativa e a promoção do desenvolvimento. Revista de Direitos Fundamentais e Democracia, Curitiba, v. 13, n. 13, p. 340-399, jan./jun. 2013.

JUSTEN FILHO, Marçal. Comentários à lei de licitações e contratos administrativos. 17. ed. São Paulo: RT, 2016.

LEITE, José Rubens Morato (Coord.). Manual de direito ambiental. São Paulo: Saraiva, 2015.

MASTRODI, Josué; BRITO, Beatriz Duarte Correa de. Licitações públicas sustentáveis: vinculação ou discricionariedade do administrador? Revista de Direito Administrativo, Rio de Janeiro, v. 274, p. 81-112, jan./abr. 2017.

MATA DIZ, Jamile Bergamaschine; CALDAS, Roberto Correia da Silva Gomes. Contratos administrativos à luz de novas formas de gestão e da sustentabilidade: por uma concretização do desenvolvimento sustentável no Brasil. A\&C - Revista de Direito Administrativo \& Constitucional, Belo Horizonte, ano 16, n. 65, p. 249-275, jul./set. 2016. 
MENEGUZZI, Rosa Maria. Conceito de licitação sustentável. In: SANTOS, Murillo Giordan; BARKI, Teresa Villac Pinheiro (Coord.). Licitações e contratações públicas sustentáveis. Belo Horizonte: Fórum, 2015. p. 21-42.

MINISTÉRIO DO PLANEJAMENTO, ORÇAMENTO E GESTÃO (MPOG). Relatório de diretrizes aos planos de gestão de logística sustentável, Brasília, 2013.

ONU. Organização das Nações Unidas. Declaração da Conferência das Nações Unidas sobre Meio Ambiente Humano, Estocolmo, 1972. Disponível em: <www.onu.org.br/rio20/img/2012/01/estocolmo1972.pdf>. Acesso em: 10 ago. 2017.

ONU. Organização das Nações Unidas. Declaração do Rio sobre desenvolvimento e meio ambiente (Agenda 21), Rio de Janeiro, 1992. Disponível em: <www.onu.org.br/rio20/img/2012/01/agenda21.pdf>. Acesso em: 10 ago. 2017.

ONU. Organização das Nações Unidas. Declaração final da conferência das nações unidas sobre desenvolvimento sustentável $(\mathbf{R I O}+\mathbf{2 0})$, Rio de Janeiro, 2012. Disponível em: <http://funag.gov.br/loja/download/RIO_+_20_O_MODELO_BRASILEIRO__PORTUGUES.pdf>. Acesso em: 10 ago. 2017.

PORTAL DE COMPRAS PÚBLICAS SUSTENTÁVEIS. Apresenta informações sobre as aquisições sustentáveis do Governo Federal. Disponível em: < http://cpsustentaveis.planejamento.gov.br/contratacoes-publicassustentaveis>. Acesso em: 10 ago. 2017.

REQUI, Érica Miranda dos Santos. As contratações públicas como instrumento de fomento ao desenvolvimento sustentável. Revista Zênite - Informativo de Licitações e Contratos (ILC), Curitiba, n. 218, p. 378-389, abr. 2012.

RODRÍGUEZ-ARANA MUÑOZ, Jaime. The principles of the global law of public procurement. A\&C - Revista de Direito Administrativo \& Constitucional, Belo Horizonte, ano 16, n. 65, p. 13-37, jul./set. 2016.

SANTOS, Fabrício Vieira dos. A legalidade das compras públicas sustentáveis. Jus Navigandi, Teresina, ano 16, n. 2.774, 04 fev. 2011. Disponível em: <http://jus.com.br/revista/texto/18421>. Acesso em: 10 ago. 2017.

SOUZA, Lílian Castro de. Política nacional do meio ambiente e licitações sustentáveis. In: SANTOS, Murillo Giordan; BARKI, Teresa Villac Pinheiro (Coord.). Licitações e contratações públicas sustentáveis. Belo Horizonte: Fórum, 2015. p. 103-115.

TORRES, Rafael Lopes. Licitações sustentáveis: sua importância e seu amparo constitucional e legal. Revista do TCU, Brasília, n. 122, p. 102-119, 2011. 